\title{
The power of social networking sites: Student involvement toward education
}

\author{
M. Norhailawati ${ }^{1}$, Lina Handayani ${ }^{2}$, HU Kalsum ${ }^{3}$, Zainuri Saringat ${ }^{4}$, A. Aidahani ${ }^{5}$, SH Bakri ${ }^{6}$, Rully \\ Charitas Indra Prahmana ${ }^{7}$ \\ ${ }^{1,3,5,6}$ Faculty of Computer Science and Information Technology, Kolej Poly-Tech MARA Batu Pahat, Malaysia \\ ${ }^{2}$ Faculty of Public Health, Universitas Ahmad Dahlan, Indonesia \\ ${ }^{4}$ Faculty of Computer Sciences and Information Technology, Universiti Tun Hussein Onn Malaysia, Malaysia \\ ${ }^{7}$ Postgraduate Program, Universitas Ahmad Dahlan, Indonesia
}

\begin{abstract}
Article Info
Article history:

Received Aug 9, 2019

Revised Sep 10, 2019

Accepted Sep 25, 2019

Keywords:

Education tools

Social Network Site (SNS)

Student involvement

Survey

ABSTRACT

Social networking web sites is not a new medium for users. The growth of this media helps students communicate and socialize with their friends or followers and used for education. The retention number of students is an issue or real problem in higher educational institutions since it is related to institution overall performance. This research focused on how students' involvement in social network web site for educational purposes can have a positive effect to their studies and can help institution to retain number of students in the institution. During the research study, students did give full cooperation and involvement in the group that created and dedicated to their collaborative learning. Facebook is the social networking website that used to support learning. The research method applied was survey and the questionnaires distributed to 40 students who got probations result (the Cumulative Grade Point Average (CGPA) was below 2.00) from various academic programs. The result showed that social network website plays an important role in education. The finding also showed that the probation students improve their CGPA and status, while the institution able to maintain their student retention number.
\end{abstract}

Copyright $@ 2019$ Institute of Advanced Engineering and Science. All rights reserved.

\section{Corresponding Author:}

M. Norhailawati,

Faculty of Computer Science and Information Technology,

Kolej Poly-Tech MARA,

7/91, Taman Shamelin Perkasa, 56100 Kuala Lumpur, Wilayah Persekutuan Kuala Lumpur, Malaysia.

Email: haila@gapps.kptm.edu.my

\section{INTRODUCTION}

A social networking website is a platform that enables user to create social relations and communicate between then. They are sharing their activities, interests' backgrounds on Social Networking Sites (SNS) such as Facebook, Instagram, Twitter, WhatsApp, Telegram, YouTube, and others. The SNS defined as category of web sites contain user profiles, reaction on user profile and publicly broadcast social networks that are displayed in connection with the profile [1].

The SNS is an application with web-based technology that is consists of rich text, sound, video, image that make communication more interactive and pleasant [2]. Trough SNS, the interaction between users is using virtual communities and networks [3]. It makes the interaction and communication more substantial and pervasive between the users, organizations, and communities [4].

Among the users, students are a large group interested in SNS. Then, this research focusing on academic activities using SNS since SNS was defined as Facebook, YouTube, Blogs, Twitter, MySpace or LinkedIn [5]. Owusu-Acheaw [6] stated that SNS is a new platform for young people to do communication among them around the world. Research that conduct by Manca and Ranieri [7] and Tess [8] showed 
Facebook had been the most researched platform for teaching and learning followed by YouTube and Twitter.

SNS are used for socially and academically purposes. Nowadays, students consider SNS as beneficial tools for social gatherings. The critical phase that students must go through is in their first year at the college. Thus, they need to communicate, socializing with other students, getting engaged with their society and adapting new environment of education or studies. Therefore, SNS plays an important role in building a relationship, maintain social engagement and to improve their education learning skills [9]. For instance, some students used SNS to present their self, to update their social lives, but some students used SNS to look at friend and to build networking among society [10].

Tinto [11] mentioned that student retention and graduation issue are important. It is because the graduation rates in universities and colleges vary considerably. Then, academic performance is important to maintain retention students in an institution. Therefore, this research focuses on student involvement in SNS for education purposes. The academic performances evaluated by collecting a survey from student with Cumulative Grade Point Average (CGPA) below than 2.00 and applying SNS in education for respondents to prove the increasing academic performance.

The usage of social media as teaching and learning tools by the teachers and students in the education field is widely implemented. Since most of their time in engaging with social media, it can help in students' engagement and teacher pedagogical practices.

\section{Higher education usage of social networking sites}

Students of higher education used and participated in various social media tools. They choose to use Facebook groups (specialty/faculty) frequently for communication, sharing information, content creation and additional learning. While chat-based applications (Skype, Viber, etc.) used when communicating with their colleagues, and for communication with teachers, the preferable channels are Email and E-learning platforms [12].

Higher education institution needs to involve actively in social media platform from the student's perspective. The most required platforms are email, Facebook and search engine Google since it also widely used by the students and did have a high impact on their study activities such as conducting research, discussion in group, completing a project, internship and else. These platforms play an important role in higher education staff to communicate or interact with the student [13].

Higher education peoples (administrator staff, members of faculty and students) have formally accepted social networking sites. This due to the nature of social networking sites that interconnected peoples and powered by latest technologies such as interactive digital and mobile [8, 14-16]. It represents a major paradigm shift in education today.

The evolution of education practices today is focussing on student-centered education that required student to play active role in the study $[17,18]$. This pedagogy will dependent on technology that available to gain effective learning especially social networking sites that allow learners to gain, explore, share and contribute new knowledge. However, the real pedagogy practices now still far from achieving the goal that design for student-centered education.

Dunn's research [16] shown that the academic setting of two approached in education needs to be aligned, which is not focussing only on teaching with technology but needs to covered learning with technology for student's academic benefit. Characteristics of the Net Gen students as those who; not prefer traditional teaching and learning pedagogy that require them to concentrate during long hours lecture or respond to lecture demand but this generation prefers to collaborative learning and require information tailored to their needs and require readily available technology. In would appear that for higher education institutions to meet the needs of the Net Gen students, approaches must change from the traditional lecture to assignments and engagements that allow for discussions, reflections, group projects and cooperative problem solving [19].

\section{Impact of social networking sites on education-system}

There are notable trends in using social media in higher education. Students proactively use various social media and channels in communication regarding the educational process [11]. Social networking sites provide students with the opportunity to communicate and collaborate with others in real-time [20].

Science Daily, June 21, 2008 [21] concluded that social networking sites could be beneficial to education. Students did proficiently with social networking technology that been exposed to them since childhood including the low-income students, and this creates tremendous educational potential. Greenhow said that social networking sites not only used for social fulfilment but it used for the formal activity, and it implicated educators. Educators today through social networking sites can share knowledge and monitor or support student-learning performance. 
The emerging of mobile social networking as a "personal web" helps students to communicate with virtual communities and organize information. It provides outside classroom walls study environment where the technology help students to continue communicated with study groups and help the teacher to update changes such as course logistics to the students. It is undeniable that social networking sites are popular among higher education students. However, its positive impact on learning still needs further studies [22].

\section{RESEARCH METHOD}

The metho begins with a theoretical framework used for the research. Figure1 is conceptual framework for analyzing student involvement toward education. To apply collaborative learning in social networking site, the main important element is suggested being considered in this research are engagement of students in social networking site. Social Networking Site (SNS) is an approach that allows groups of students work together to discuss the learning material. The SNS can increase interaction among students and interaction among students and lecturers as well [23].

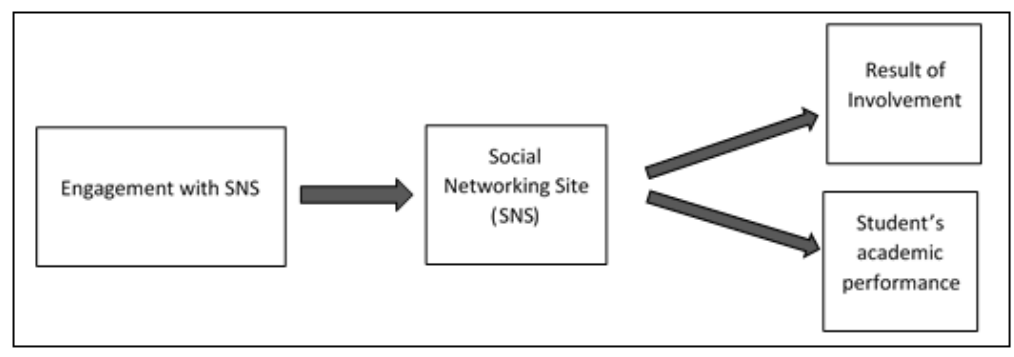

Figure 1. Conceptual framework of SNS toward education.

Figure 1 shows that there are four elements involved. The first element is engagement with SNS as an input in which students must have Facebook accounts. Those students do not have Facebook account need to create a new one. Then, Facebook was selected as SNS because the capabilities of Facebook can upload/download files, discussion online and more. The SNS as process tool to show the resulting involvement of students and their performances. The output is focusing on academic performance and usage SNS in education. The result will discuss in the topic Results and Discussion.

\subsection{Research approach}

The research approach chose for this research is the quantitative approach, which the data is in the form of selective numbers [24]. This method able to read person's behaviour. When the person fills the form, data easily to analyze based on value, and it will be used to get the solid measurements. Normally researchers used survey and questionnaires as tools in the quantitative approach [25].

\subsection{Research design}

The approach used to design the research is using descriptive research. Hence, this method chose quantitative research, the information gathered by using a descriptive approach. The descriptive approach involved collecting data that explain situations and the method will organize, depicts, tabulate and defines the data collection [24-26]. To give better understanding of the research's finding, the method typically supported with visual aids like graphs and charts. For this research, the sources of literature were analyzed and collected information where the usage of SNS and the use of SNS for education purposes.

\subsection{Population and sampling}

For this research, about 40 respondents were selected and involved. The respondents were those students who were the CGPA was below 2.00 from various programs, and those who had probation result. The target group found based on result on previous semester. This research was focused on respondents' CGPA below 2.0 and probations result because it will convince the facts how effectiveness of using SNS to get better performance especially in academic fields [27]. The sampling was from Kolej Poly-Tech MARA Batu Pahat students. The programs for students involved were from Diploma in Computer Systems and Networking and Diploma in Computer and Graphic Design.

There were seven courses and lecturers selected to participate in this research. The courses were chosen base on respondents involved in this research, and the lecturers were chosen according to the course 
selected. The social networking site chose Facebook. All respondents were invited into the group and lecturers will post learning material to the site group named SNS Group. When lecturer has posted learning material, student will able to view the material and involve with any discussion with the other students in the same group.

\subsection{Survey and questionnaires}

The survey was conducted through offline. The instrument used is questionnaires. The set of the questionnaire was distributed to those students that were selected based on their CGPA's result. These surveys provide two languages, Bahasa Malaysia and English. Respondents able to select choice more than one answer. Data collected from these surveys.

There are three parts surveys in these questionnaires. The first part, respondent's basic information: age and gender. The second part questions about information and involvement respondents about SNS. They were asked about their knowledge on SNS, and if they have an SNS account, they have to proceed to all the questions. However, if the answer is no, they should end the survey. In this section, respondents need to disclose the duration they joined in the SNS, the reason to join, hours spend daily, the number of friends they have, and how long the period they $\log$ in to the sites daily. This section is to investigate how depth they participate in the SNS and the respondents' behaviour towards the site. The last part is about the educational of privacy matters. The awareness of using SNS and the purposes were determined from this part.

\section{RESULTS AND DISCUSSION}

In the research, we discussed several matters between SNS and education: the usage, effect on teaching and learning activities, and effects on grades performance as well.

\subsection{Use social network sites to support education}

Respondents been asked about their experience using social networking sites for educational purposes. The result showed $30 \%$ of respondents often make use of social networking sites as their educational support besides the class activities. About $60 \%$ of the respondents rarely used social networking sites for educational purposes, and $10 \%$ never used social networking sites to support their education. The result is shown in Figure 2.

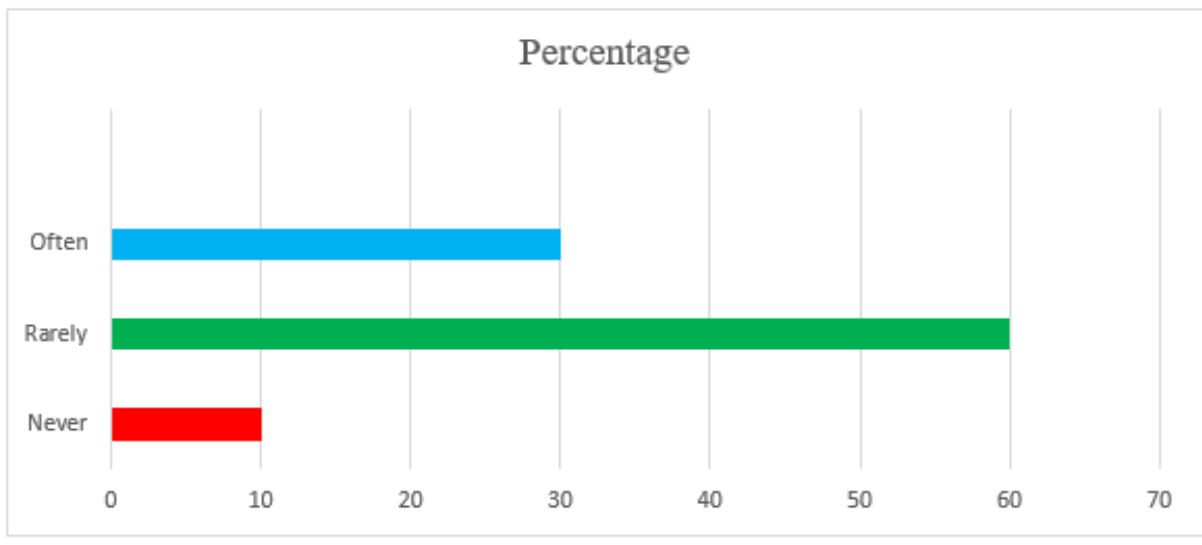

Figure 2. Frequency of used SNS for education

\subsection{Effect of social network sites on teaching and learning}

There is a survey question about the impact of social networking sites on their education. About 92.5\% respondents feel that social networking sites will give benefits for their education that can be seen in Figure 3. 


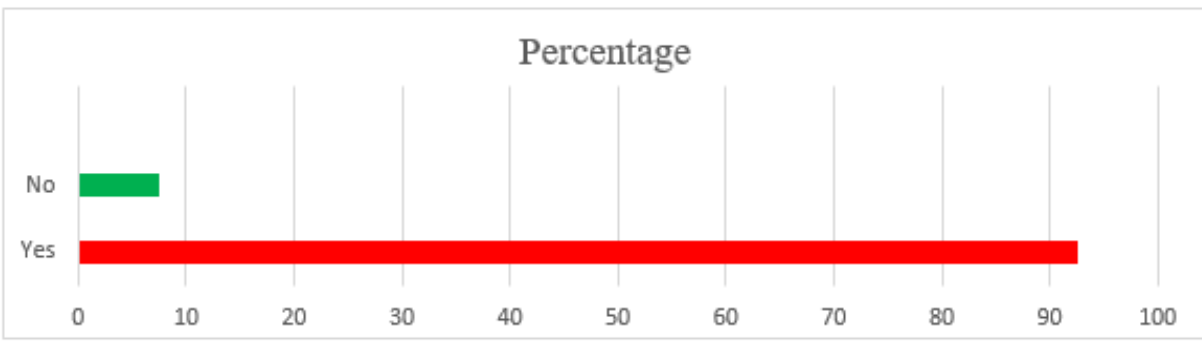

Figure 3. Benefits of social networking site for education

About $77.5 \%$ of respondents agreed that social networking sites would give positive effect on teaching and learning activities. About $10.0 \%$ of respondents feel that social networking sites will give them no effect on their teaching and learning. Meanwhile, about $12.5 \%$ of respondent feel that social networking sites give negative impact. Figure 4 has the result.

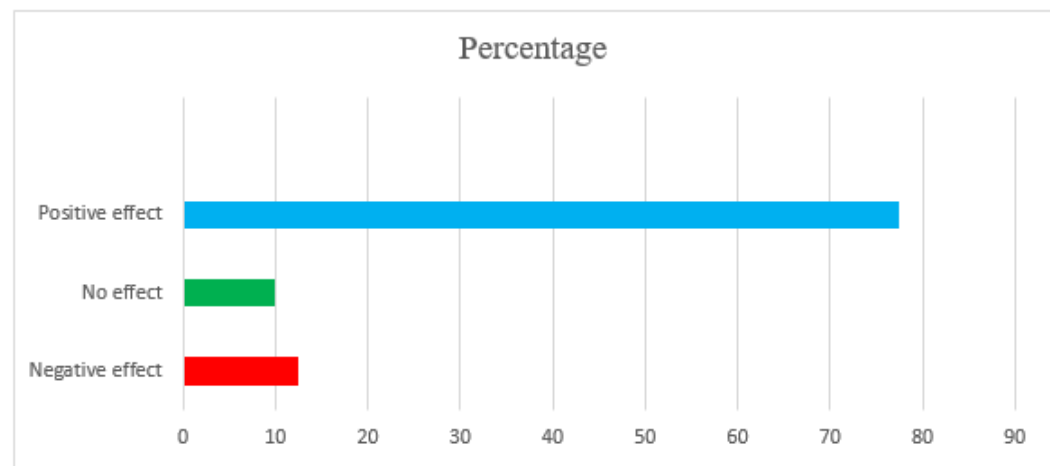

Figure 4. Effects of SNS in teaching and learning activities

\subsection{Effect of social network sites on grades performance}

Besides the effect on teaching and learning, respondents also been asked about the effect of social networking sites on respondents' grades or performance. About $52.5 \%$ of them agreed that the usage of social networking sites would help them improve their grades. However, about $27.5 \%$ of respondents stated that social networking sites would not affect their grades or performance. The result of this question shown in Figure 5.

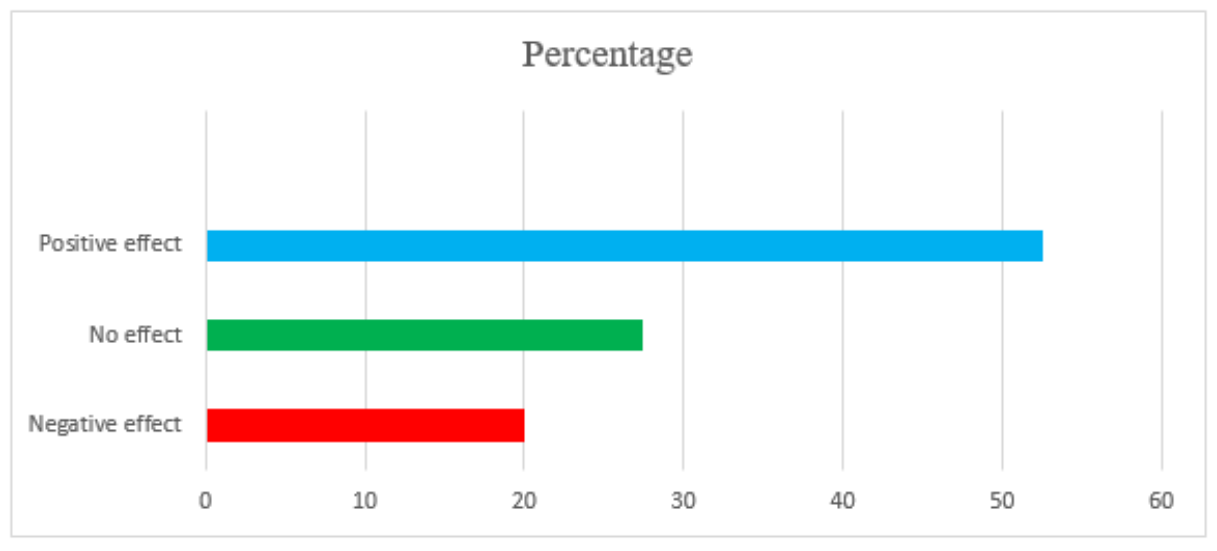

Figure 5. Effect of SNS on grades or performance student 


\subsection{Social network sites to discuss educational work}

Respondents have also been asked about did they use social networking sites to discuss their educational work. This question is to identify the usage of social networking sites towards education elements by the respondents. About $67.5 \%$ of them rarely used SNS to discuss their educational work. Figure 6 describes the result of the survey about this matter.

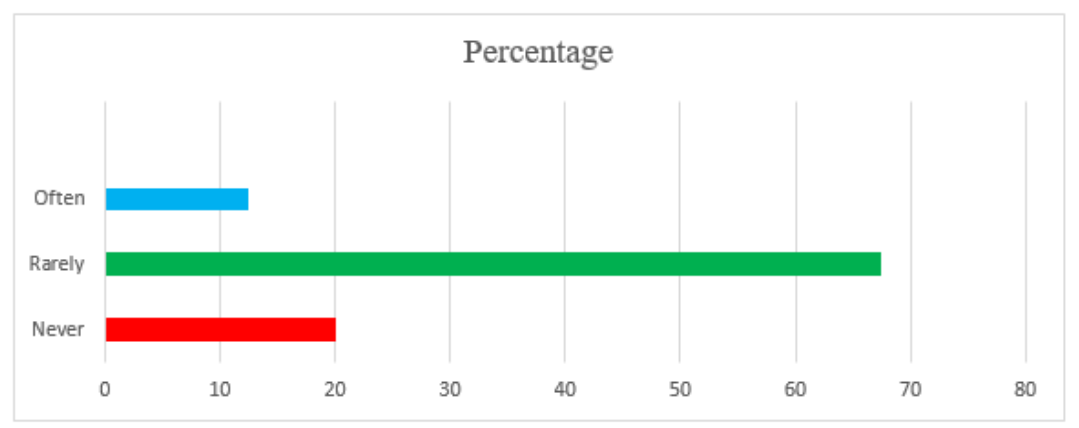

Figure 6. SNS usage to discuss educational work

\subsection{Social network sites and educational institution}

The educational institution also plays important role in the usage of social networking sites to support education. Practically, about $87.5 \%$ of respondents agreed that education institutions well use SNS to support education for them. The rest considered that educational institution has no role in supporting education system with social networking sites usage.

Table 1 shows the result of a statement agreed by respondents about SNS and education. About $80.0 \%$ of respondents claimed SNS helped them to keep in touch with classmates. SNS also helps 52.5\% respondents to develop their social skills virtually. Besides, about $50.0 \%$ of respondents also agreed that by involving in SNS, it would not disturb them with their educational work.

Table 1. SNS and education

\begin{tabular}{ll}
\hline A statement that represents social networking sites and education & Percentage (\%) \\
\hline Social Network Sites do not help me keep in touch with classmates or colleagues. & 0 \\
Social Network Sites do not help to develop my social skills. & 0 \\
Social Network Sites cause a distraction to my educational work & 12.5 \\
Social Network Sites play no role in my campus life & 2.5 \\
Social Network Sites play a large role in my campus life & 50.0 \\
Social Network Sites help me keep in touch with classmates & 80.0 \\
Social Network Sites do not distract me from my educational work & 50.0 \\
Social Network Sites are very useful to me academically & 32.5 \\
Social Network Sites are of no use to me academically & 7.5 \\
Social Network Sites help to develop my social skills & 52.5 \\
\hline
\end{tabular}

\subsection{Social network sites and role in education}

SNS provides several criteria that can help and support education. About $75.0 \%$ of them agreed that SNS has important role in the future of education. The result is described in Figure 7.

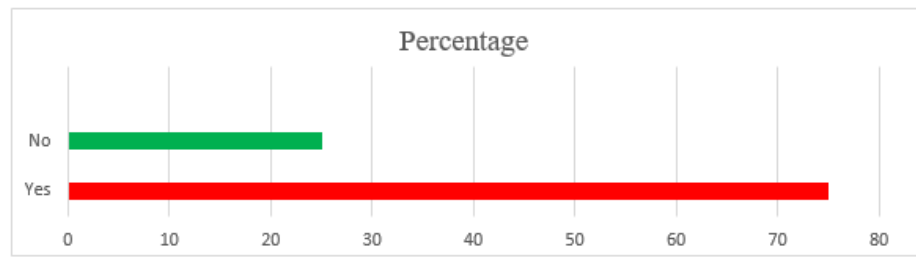

Figure 7. Students agreed with the important role of SNS in future education 
The result shows that about $60 \%$ of the respondents rarely use social networking sites for education. About $87.5 \%$ of respondents never and rarely use social networking sites to discuss education matters. Even though the respondents do not show interest in using the sites for education, about $92.5 \%$ of them believed that social networking sites are beneficial and can be used to help students in their study. It is because most of them agreed that involving in SNS will help them to keep in touch with their classmates, will not distract them from their educational work and will help them to develop their social skills.

Survey also mentioned that about $77.5 \%$ of respondents agreed that the sites could give positive effect on teaching and learning process (to both students and lecturers). Thus, about $52.5 \%$ decided the social networking sites also would give good impact on their study grades and achievement. The educational institution also plays important role in making the social networking site as teaching and learning medium. Respondents been asked about the facilities and contribution of educational institutions towards the usage of the site. Almost $87.5 \%$ of them agreed that the institute would use social networking sites in teaching and learning. Social networking sites also help many students as resources to support their projects [28-34].

\section{CONCLUSION}

The respondents rarely either use social networking sites for educational purposes for support education or discuss educational work perhaps for some reason. However, they believed that social networking sites have benefits and it will help them achieve good grades. They also agreed that the social networking site would play a large role in their campus life. They also thought that with the wide usage of web 2.0, social networking sites might play important roles in supporting education.

\section{ACKNOWLEDGEMENTS}

This work is sponsored by MARA under grant MARA/UNI: 1/33/05/07/14.

\section{REFERENCES}

[1] X D. Boyd, "Friends, Friendsters, and MySpace Top 8: Writing community into being on social network sites," First Monday, vol. 11(12), pp. 1336, 2006.

[2] N. K. Asiedu, "Influence of social networking sites on students' academic and social lives: The Ghanaian Perspective," Library Philosophy and Practice (e-journal), pp. 1535, 2017.

[3] K. Bala, "Social media roadmaps: Social Media and changing communication patterns," Global Media JournalIndian Edition, vol. 5(1), pp. 1-6, 2014.

[4] J. H. Kietzmann, K. Hermkens, I. P. Mccarthy, and B. S. Silvestre, "Social media? Get serious! Understanding the functional building blocks of social media," Business Horizons, vol. 54(3), pp. 241-251, 2011.

[5] T. D. Baruah, "Effectiveness of Social Media as a tool of communication and its potential for technology enabled connections: A micro-level study," International Journal of Scientific and Research Publications, vol. 2(5), pp. 110, 2012.

[6] M. Owusu-Acheaw and G. L. Agatha, "Use of social media and its impact on academic performance of tertiary institution students: A study of students of Koforidua Polytechnic, Ghana," Journal of Education and Practice, vol. 6(6), pp. 1735-2222, 2015.

[7] S. Manca and M Ranieri, "Is it a tool suitable for learning? A critical review of the literature on Facebook as a technology-enhanced learning environment," Journal of Computer Assisted Learning, vol. 29(6), pp. 487504, 2013.

[8] P. A. Tess, "The role of social media in higher education classes (real and virtual)-A literature review," Computers in Human Behavior, vol. 29(5), pp. A60-A68, 2013.

[9] M. Tayseer, F. Zoghieb, I. Alcheikh, and M. N. Awadallah, "Social Network: Academic and social impact on college students," ASEE Zone 1 Conference, 2014.

[10] A. M. Megan, K. Rajitha, S. Shari, and M. W. Jennifer, "The Facebook influence model: A concept mapping approach," Cyberpsychology, Behavior and Social Networking, vol. 16(7), pp. 504-511, 2013.

[11] V. Tinto, "Enhancing student persistence: Lessons learned in the United States," Análise Psicológica, vol. 24(1), pp. 7-13, 2012.

[12] Y. Aleksandrova and S. Parusheva, "Social media in higher education from students' perspective," 4th International Multidisciplinary Scientific Conferences on Social Sciences \& Arts Sgem, vol. 1(4), pp. 709716, 2017.

[13] Z. Wang, J. M. Tcherven, and T. Solloway, "A dynamic longitudinal examination of social media use, needs, and gratifications among college students," Computers in Human Behavior, vol. 28(5), pp. 1829-1839, 2012.

[14] P. J. Voorn and P. Kommers, "Social media and higher education: Introversion and collaborative learning from the student's perspective," International Journal of social Media and Interactive Learning Environment, vol. I(1), pp. $59-71,2013$. 
[15] J. H. Waldeck and K. Dougherty, "Collaborative communication technologies and learning in college courses: Which are used, for what purposes, and to what ends?," Learning, Media and Technology, vol. 37(4), pp. 355378, 2012.

[16] L. Dunn, "Why it's Time to Start BOYD in Your School on Edudemic," Retrieved January 11, 2013, from http://edudemic.com/2012/12/why -its-time-to-start-byod-in-your-school/, 2012.

[17] A. F. Jannah and R. C. I. Prahmana, "Learning fraction using the context of pipettes for seventh-grade deaf-mute student," Journal for the Education of Gifted Young Scientists, vol. 7(2), pp. 299-321, 2019.

[18] H. Hendriana, R. C. I. Prahmana, and W. Hidayat, "The innovation of learning trajectory on multiplication operation for rural area student in Indonesia," Journal on Mathematics Education, vol. 10(3), pp. 397-408, 2019.

[19] G. Beqiri, "The impact of social media on higher education in Kosovo: The student's perspective," International Journal of Interdisciplinary Research SIPARUNTON, vol. 3(2), pp. 155-163, 2014.

[20] N. C. Camilia, S. D. Ibrahim, and B. L. Dalhatu, "The effect of social networking sites usage on the studies of Nigerian students," The International Journal of Engineering and Science, vol. 2(1), pp. 39-46, 2013.

[21] University of Minnesota, "Educational benefits of social networking sites uncovered," Science Daily. Retrieved February 28, 2018 from www.sciencedaily.com/releases/2008/06/080620133907.htm., June 21, 2008.

[22] M. Salvation and N. A. Adzharuddin, "The influence of Social Network Sites (SNS) upon academic performance of Malaysian students," International Journal of Humanities and Social Science, vol. 4(10), pp. 131-137, 2014.

[23] R. C. Jr. Fernando, K. Claudia, and O. Bert, "Teachers and facebook: Using online groups to improve students' communication and engagement in education," Communication Teacher, vol. 30(4), pp. 228-241, 2016.

[24] P. M. Nardi, "Doing survey research: A guide to quantitative methods (4th Ed)," United Kingdom: Routledge, 2018.

[25] D. Ary, L. C. Jacobs, C. K. S. Irvine, and D. Walker, "Introduction to research in education," Boston, MA: Cengage, 2018.

[26] R. D. Wimmer and J. R. Dominick, "Mass media research an introduction (7th Ed.)," Belmont, CA: Thomson Wadsworth, 2006

[27] A. Susilo, "Exploring facebook and whatsapp as supporting social network applications for english learning in higher education," Teaching and Learning in the 21st Century: Challenges for Lecturers and Teachers, vol. 1(1), pp. 10-24, 2014.

[28] H. I. Gurcan, "Contribution of social media to the students' academic development," International Journal of Information and Education Technology, vol. 5(12), pp. 965-968, 2015.

[29] U. E. Umoh and E. N. Etuk, "Students' involvement in social networking and attitudes towards its integration into teaching," International Education Studies, vol. 9(9), pp. 250-260, 2016.

[30] S. Mehmood and T Taswir, "The effects of social networking sites on the academic performance of students in college of applied sciences, Nizwa, Oman," International Journal of Arts and Commerce, vol. 2(1), pp. 111$125,2013$.

[31] H. Kamaludin, S. Kasim, N. Selamat, and B. C. Hui, "M-learning application for basic computer architecture," In 2012 International Conference on Innovation Management and Technology Research, pp. 546-549, IEEE, 2012.

[32] D. Muhtadi, Wahyudin, B. G. Kartasasmita, and R. C. I. Prahmana, "The Integration of technology in teaching mathematics," Journal of Physics: Conference Series, vol. 943(1), pp. 012020, 2018.

[33] S. Kasim and F. A. Zakaria, "Daily calorie manager for basic daily use," In Third International Conference on Innovative Computing Technology (INTECH 2013), pp. 437-442, IEEE, 2013.

[34] S. Kasim and B. S. Wai, "Multilingual phrasebook for Android (MPA)," In Third International Conference on Innovative Computing Technology (INTECH 2013), pp. 443-448, IEEE, 2013. 